\title{
Idéias do poder: dependência e globalização em F. H. Cardoso*
}

\author{
SEBASTIÃO C. VELASCO E CRUZ
}

“... não existe (senão logicamente) uma nítida separação entre conceito e história, entre teoria e política."

"Importa pouco ... saber quem formulou tal ou qual categoria ou tipo de análise. ... O que importa é mostrar que, na medida em que uma perspectiva teórica vai se concretizando, ela vai englobando e especificando mais relações e, simultaneamente, vai se incorporando à prática social e política, tornando-se 'verdade concreta'" (1).

A TEORIA DA DEPENDÊNCIA pode ser e tem sido discutida a partir de uma infinidade de pontos de vista, alguns mais, outros menos frutíferos. Contudo, neste momento em que ela atinge 30 anos, o debate sobre sua trajetória estaria incompleto se não contemplasse também o problema de sua relação com a realidade sócio-econômica e política que ela procurou refletir e pretendeu transformar.

Presente, desde o início, na reflexão que os teóricos da dependência faziam a respeito de seu próprio trabalho, esse tema - das relações recíprocas entre teoria e prática, formas de pensamento e processos de transformação histórica - tem despertado crescente interesse em variados campos da Sociologia e da Ciência Política. Os títulos se multiplicam. Basta mencionar, à guisa de exemplo, a importante coletânea sobre a difusão internacional do keynesianismo organizada por Peter Hall (2). Sob variados registros, ele aparece também no campo das Relações Internacionais, estando mesmo no centro da controvérsia teórico-metodológica

* Texto apresentado no seminário Teoria da dependência: 30 anos depois, organizado pelo Instituto de Estudos Avançados da USP em 15 de junho de 1998 na Universidade de São Paulo, com a colaboração dos Departamentos de Economia da FGV e da PUC-SP e dos Departamentos de Sociologia e de Ciência Política da FFLCH-USP. 
que agita essa área, tradicionalmente tão indiferente às comoções freqüentes em outros domínios das Ciências Sociais (3).

No caso da teoria da dependência, a circunstância muito especial de um de seus autores ter assumido o comando político de um país como o Brasil, em período de crise e profundas mudanças institucionais, produziu desde o início um aceso debate. Ainda durante a campanha presidencial, o tema aparecia na imprensa, como o fio condutor de um artigo longo, fortemente crítico e finamente pensado, que mereceu do autorcandidato pronta e respeitosa resposta (4). Para além das muitas diferenças que os separavam, um e outro coincidiam neste ponto decisivo: entre as análises sociológicas passadas e a prática política presente do personagem em causa existiria uma grande continuidade. Nem todos, porém, aceitam esse ponto de vista. Muitos resistem em reconhecer na ação atual do homem público a marca de suas antigas idéias. "Esqueçam tudo que eu escrevi". Para esses, apesar do reiterado protesto do suposto autor, continua valendo, mais ou menos atenuadamente, a mensagem contida na frase famosa.

A controvérsia envolve três questões de natureza diversa:

- O aludido problema teórico-metodológico da relação entre idéias e ação, pensamento e prática; no âmbito em que estamos nos movendo, ele se traduz nas perguntas: em que medida, na definição das políticas adotadas por governos, as idéias de seus dirigentes importam? Como entender a sua incidência? Como um fator discreto a condicionar a definição e a implementação de políticas, ao lado de outros, como possam ser as instituições e o jogo das alianças entre atores sociais (ou alianças de classe)? Se é assim, que peso lhe atribuir? Tomá-lo como elemento importante, ou claramente subordinado? Como enfrentar a questão? Tratá-la como um problema teórico, a ser resolvido pela análise conceitual, ou tomá-la como questão empírica, admitindo que o valor dessa variável se altera segundo uma ordem que devemos nos esforçar para entender? (5)

- A questão das relações entre idéias de um autor em momentos diferentes de sua vida intelectual; o problema sempre espinhoso da continuidade e das rupturas no percurso de uma obra.

- O problema da conexão entre o pensamento expresso pelo autor em determinada fase de sua trajetória pessoal e o comportamento que ele exibe, anos depois, como agente histórico. 
Essas questões são freqüentemente confundidas. Convém separálas. Quando mais não fora, pelo menos para sair do esquematismo da oposição binária. Com efeito, a consideração conjunta desses três aspectos nos deixa com várias possibilidades, como sugerido na figura a seguir.

\section{$+\mathrm{A} \quad \mathrm{B}$}

Continuidade

de pensamento

$$
\begin{gathered}
\text { C D } \\
- \\
\text { Correspondência } \\
\text { idéias/política }
\end{gathered}
$$

Na figura, podemos ver claramente demarcadas quatro posições extremas. Mas basta o leitor deslocar-se mentalmente pelas duas linhas que ligam esses pontos na diagonal para perceber que as possibilidades historicamente plausíveis podem ser em número muito mais elevado.

No Brasil, o debate a respeito dos antecedentes intelectuais da política conduzida por Fernando Henrique Cardoso tem se concentrado na terceira das questões mencionadas. Levando em conta a discussão esboçada neste artigo até aqui, vou abordá-la sob um prisma diverso. Sem me deter no problema teórico nele aflorado - darei por assentado que as idéias realmente contam - começarei pelo primeiro item, mas invertendo os seus termos: ao invés de indagar sobre como as idéias influenciam as políticas, tomarei as políticas do poder como dadas, para interrogar que idéias são as suas. Tal passo me conduz diretamente ao segundo item. Nesse sentido, tomando caminho inverso ao da cronologia, começarei examinando com a máxima atenção possível as formulações mais recentes de Cardoso sobre as propriedades emergentes da economia mundial neste final de século e as implicações que elas encerram para países como o nosso. Com esse exercício pretendo avaliar o maior ou menor grau de convergência entre o discurso atual e as antigas análises sobre a dependência. Espero ainda colher elementos que me permitam avançar na questão levantada no início deste artigo entre a teoria da dependência e a ação de seu autor, como chefe de Estado. 
Para tais fins, tomarei como campo privilegiado de observação três importantes documentos, todos dedicados especificamente ao tema da configuração presente da economia mundial: a conferência pronunciada por Fernando Henrique Cardoso em Nova Déli, em janeiro de 1996, sob o título Conseqüências sociais da globalização; a conferência lida por ele no Colégio do México, em 20 de fevereiro do mesmo ano, intitulada $O$ impacto da globalização nos paises em desenvolvimento: riscos e oportunidades (6), a palestra Globalização e politica internacional, feita em Johannesburgo, África do Sul, em 27 de novembro do mesmo ano. Complementarmente, usarei ainda quatro longas entrevistas nas quais Fernando Henrique Cardoso discorre sobre esses e outros assuntos, já como titular da Presidência da República: a primeira, concedida a Roberto Freire, Domingos Leonelli e José Genuíno, saiu na revista Esquerda 21 em 1995; a segunda, dada a Brasílio Sallum Jr., foi publicada na revista Lua Nova (7); a terceira, ocupa três páginas do jornal Gazeta Mercantil, em sua edição de 19 de junho de 1997; completa a lista a rumorosa entrevista que saiu na Veja em setembro do ano passado. No trabalho com esse material, levo em conta, por fim, alguns textos de sua autoria que versam sobre o tema deste artigo e que foram escritos no início da década de 90 (8).

Dois esclarecimentos adicionais:

- Como deve estar claro a esta altura, na discussão desses textos o meu interesse não está voltado para o valor de verdade de seus enunciados (embora, em alguns casos, para esclarecer o significado de uma ou outra passagem essa dimensão não possa ser contornada).

- Para que seja viável, um exercício como o proposto aqui deve supor sejam conhecidas, em suas linhas gerais, tanto as teses originais de Cardoso sobre a dependência quanto a política que, uma vez no governo, ele pratica agora.

A observação acima me conduz ao comentário com o qual encerro estas páginas introdutórias. Ao iniciar o estudo que resultou neste artigo, cedo percebi a existência de uma dificuldade extrínseca bastante espinhosa. Tratava-se de examinar com a maior objetividade possível certo aspecto da atividade intelectual de um político no exercício do poder, o qual, por suas ações e omissões, desperta cotidianamente no público brasileiro sentimentos fortes - devo dizer isso a leitor, quase sempre negativos no meu caso. Como afastar essa interferência? Como evitar que os lances da pequena política desviem a atenção dos movimentos mais amplos e profundos, atraindo-a para o plano mesquinho em que eles se desenvolvem? 
A forma que encontrei para enfrentar o problema foi a de realizar um esforço consciente e sustentado de distanciamento, a fim de buscar na prática do intelectual a presença sempre dominante do político, e na atividade deste a marca nunca ausente do intelectual. Estou consciente de que, ao proceder assim, faço o exercício de uma dupla impertinência: em contraste com a atitude recorrente em seus críticos de esquerda, levo a sério a atuação do político Fernando Henrique Cardoso, quando ele se manifesta como intelectual; em completa dissonância com o comportamento típico no séquito de seu admiradores, disponho-me a cobrá-lo pelo que diz nessa qualidade. Espero que, no final, os resultados obtidos compensem os custos que incorro ao realizá-la.

"A globalização tornou-se uma espécie de palavra da moda. Muitas vezes dita, mas raramente com o mesmo significado. Trata-se ... de um daqueles conceitos tão amplos, que é empregado por diferentes pessoas para explicar fatos de natureza completamente diversa." Essas palavras, que abrem a conferência de Fernando Henrique Cardoso em Nova Déli, retratam uma indiscutível realidade. De fato, mesmo se fixarmos nossa atenção no discurso de especialistas, ignorando o uso que se faz desse vocábulo na linguagem corrente de jornalistas e homens de negócios, logo perceberemos que estamos a tratar de uma noção extremamente lábil. Para falar apenas em graus de generalidade, os significados a ela atribuídos variam numa escala imensa, na qual um dos extremos pode ser buscado em Michael Porter e o outro no sociólogo Roland Robertson. Para o primeiro, o termo globalização tem como referente, não a economia mundial como um todo, mas indústrias particulares, e o que ele indica é a interpenetração de mercados, com a consequënte mudança na forma de concorrência interfirmas - do padrão multidoméstico, para outro, de rivalidade global (9). Para o segundo, o conceito de globalização cobre todos os dominíos da realidade social e se aplica ao conjunto de processos particulares que levam à "estruturação concreta do mundo como um todo" (10). Porter vê na "globalização" um fenômeno recente (configura-se mais claramente a partir do final da década de 1960); já para Robertson, "overall processes of globalization ... are at least as old as the rise of the so-called world religions two thousand and more years ago" (11). Em meio a tal cacofonia, ao falar em globalização, como se expressa nosso personagem?

Nos escritos e na fala de Cardoso sobre o tema, dois aspectos chamam a atenção de imediato. O primeiro diz respeito à abrangência do 
termo globalização, tal como ele o emprega. Embora, ao discutir o assunto, faça alusão muitas vezes a fenômenos sócio-culturais, estes aparecem como partes de um domínio exógeno, que recebe permanentemente o impacto da globalização, mas preserva sua autonomia e integridade. A globalização da qual ele fala tem como referente exclusivo a economia. Nos textos examinados, não encontrei um parágrafo sequer sobre os circuitos transnacionais de comunicação, sobre a difusão de valores, subculturas, estilos de vida e formas de sensibilidade em escala planetária - temas centrais, não apenas em um autor como Robertson, mas na agenda, mesma, do debate sociológico contemporâneo (12). Tampouco aparecem naqueles textos qualquer comentário sobre a "globalização" dos conflitos sociais, a eventual emergência de uma "sociedade civil global", ou sobre "estruturas de governo supranacionais" - pedra de toque, este último, da escola de pensamento político que advoga o projeto de uma "democracia cosmopolita" da qual, provavelmente, David Held é o representante mais destacado (13). Pelo contrário, em suas análises a globalização (econômica) convive pacificamente - no plano da cultura e da política - com identidades nacionais - e talvez as reforce. Mas essa tese é apenas afirmada. No que pude ler, não vi argumento algum que a apoiasse.

$\mathrm{O}$ segundo aspecto diz respeito à radicalidade da mudança que se expressa no termo globalização, e a ambivalência da mesma quando vista através de seus olhos. "Nós estamos passando por várias revoluções. A última, a mais notável é a da informática. ... O aumento da produtividade é brutal ... estamos vivendo um momento em que a aventura humana ganha uma dimensão nova. É como aconteceu no periodo do Renascimento ..." (14). Se em alguns trechos do discurso de Cardoso a glo-balização aparece assim, com ares de festa, em outros ela surge pesada e ameaçadora, como matriz de desigualdades mais fundas e exclusões novas: " $O$ mundo pode ser dividido entre as regiões ou paises que participam do processo de globalização e usufruem seus frutos e aqueles que não participam. Os primeiros estão geralmente associados à idéia de progresso, riqueza, melhores condições de vida; os demais, à exclusão, marginalização, miséria. (...) A marginalização, todavia, não está confinada unicamente aos paises ainda não integrados na economia internacio-nal. Ela também está crescendo nos próprios países prósperos" (15).

Berço de um mundo novo - mais rico, mais livre, mais dinâmico; geratriz de anomalias perversas. Ao falar da globalização, a ênfase de Cardoso cai na primeira de suas duas faces. Mas o quê, mais precisamente, ele quer dizer com essa palavra? 
Em certo plano, a resposta de Cardoso a essa pergunta segue de perto o discurso convencional. E, como este, ela é vaga, imprecisa, lacunar. Ao caracterizar o fenômeno da globalização, Cardoso menciona a "sempre crescente expansão dos fluxos financeiros internacionais", salientando o impacto negativo destes sobre a autonomia dos Estados na gestão das políticas monetária e cambial; assinala rápida expansão do comércio internacional - que supera o ritmo de crescimento do produto agregado, e enfatiza a importância cada vez maior do comércio interfirmas, levando a "uma acirrada competição entre os paises por investimentos externos".

O elemento decisivo, porém, encontra-se em outro lugar. O que há de radicalmente novo na economia mundial deste final de milênio é que os avanços espetaculares das tecnologias de transporte e de comunicação tornaram possível a integração produtiva em escala planetária. "Quando Enzo Faletto e eu trabalhamos na construção da Teoria da Dependência, o substrato do desenvolvimento na periferia do capitalismo, especialmente na América Latina, eva a internacionalização dos mercados. Porém, naquele momento, um outro fenômeno se desenhava ... concomitante com a internacionalização dos mercados, o que estava ocorrendo na América Latina e no Ocidente desenvolvido, era a internacionalização da produção" (16). Desagregando espacialmente as diferentes fases do processo produtivo, esse desenvolvimento conduz à redução contínua do conteúdo nacional dos bens produzidos, condenando definitivamente as estratégias de substituição de importações e os projetos de desenvolvimento nacional de caráter autárquico.

A internacionalização produtiva é o traço mais marcante e parece constituir o fundamento da economia global em gestação. Contudo, ela não representa uma novidade nos trabalhos de Cardoso. Podemos encontrar referências a esse fenômeno em textos de sua autoria datados de quase 20 anos atrás como, por exemplo, no período que passo a citar: " $a$ contribuição original dos latino-americanos foi a de mostrar que a partir de meados dos anos cinqüenta ... havia uma nova dinâmica no capitalismo internacional, impulsionado pelas empresas multinacionais, e que ela levaria a uma nova divisão internacional do trabalho. Estava em curso a internacionalização da produção capitalista [grifo do autor]. A linha de separação entre o mercado interno e externo se redefinia..." (17). Ou, ainda, neste outro: "Mesmo que parte da produção seja exportada e que os 'circuitos fechados' intermultinacionais redistribuam entre si parte dos componentes dos produtos finais ..." (18).

Acho importante remeter o leitor a essas passagens porque, em cotejo com as proposições mais recentes, elas põem em relevo um ponto 
obscuro e um espaço vazio no discurso presente de Cardoso sobre a economia mundial.

Ponto obscuro: a periodização. Afinal, a globalização de que ele nos fala é um fenômeno realmente novo, ou já estava esboçado em meados dos anos 50, cabendo aos latino-americanos o mérito de ter reconhecido esse fato? Se é assim, a categoria mais adequada para descrever a situação emergente - no conjunto de suas expressões e em toda sua complexidade continuaria sendo a da dependência. E caberia perguntar, então, o que se ganha em trocá-la pela noção muito mais tosca de economia global:

Mas pode ser que a primeira seja a alternativa correta. Que a globalização seja percebida como uma novidade radical, distintiva destas duas últimas décadas. Haveria, então, razões de sobra para abandonar os velhos conceitos, mesmo que provisoriamente fosse necessário, em troca, operar com categorias menos trabalhadas. Mas, nesse caso, seria preciso oferecer algo mais específico do que a "internacionalização da produção capitalista" para justificar o juízo adotado. Na ausência de maiores esclarecimentos, limito-me a registrar a obscuridade.

Espaço vazio: as grandes empresas, os conglomerados internacionais. Ao mencionar os traços característicos da globalização, no entender de Cardoso, mencionei o comércio interfirmas. Esse fenômeno já era aludido no texto de 1980. Mas entre a análise passada e as formulações atuais há uma diferença notável. Naquela, as firmas multinacionais surgem como agentes ativos - centros de acumulação e unidades de poder, a um tempo -, integrando-se em circuitos dentro dos quais uma sorte de planejamento privado parece operar. Nestas, dificilmente nos deparamos com a figura antes imponente da firma multinacional.

Suspeito que haja aí mais do que um lapso. E o que me leva a pensar assim é a compatibilidade entre esse silêncio e a maneira como Cardoso aprecia, do ponto de vista sociológico, o significado da globalização para o capital. Em suas palavras: "Na dimensão do Capital, um dos aspectos a ressaltar é o de que assistimos a uma verdadeira pulverização de sua propriedade. Hoje, os fundos de pensão e de investimento detêm ... posiçãa estratégica no controle do Capital e na definição de sua utilidade. Isso está diluindo e despersonalizando a relação patrão-empregado nos setores mais dinâmicos e modernos da economia ..." (19). Neste contexto, a relação empreendedor-empresa se altera; o detentor do saber especializado e inovador substitui o capitão de indústria. Cardoso indica que esse fenômeno vem sendo descrito desde os anos 50 (poderia acrescentar que o discutiu longamente em trabalho anterior a 1964 (20), e que ele fora definitiva- 
mente incorporado na literatura especializada, desde a publicação da obra de Berle \& Means, A moderna sociedade anônima e a propriedade privada, no início da década de 30 ), mas assinala que ele "se reforçou muito nos últimos anos". Como exemplo desse fenômeno, Cardoso cita o peso cada vez maior que os fundos de pensão vêm assumindo no Brasil, e encerra o argumento com a pergunta retórica: "Ora, como falar, hoje, com nitidez em exploração do capitalista, de rea-lização da mais-valia, no sentido clássico do marxismo, se uma parcela importante dos trabalhadores começa a tornar-se sócia do Capital"? (21)

$\mathrm{O}$ argumento desconcerta. Nele se conjugam um anacronismo patente e uma embaraçosa confusão teórico-conceitual. O leitor deve se perguntar o que esta referência à "exploração" e à "mais valia" estão fazendo aí, num texto construído, todo ele, em outra linguagem. Mas seguir esta linha seria dar prova de grave incompreensão. Essa passagem não importa pelo que diz sobre o real. Ela é significativa apenas porque manifesta, de forma gritante, as motivações do político na fala do intelectual (22).

Seja como for, no entender de Cardoso a globalização nos projeta no limiar de uma nova era. Mantemos ainda um pé em terreno conhecido, posto que a globalização "na verdade, leva ao extremos tendências do capitalismo". Mas o outro está como que suspenso, parecendo mover-se em direção a um solo que ainda não logramos identificar. "É como se o avanço do modo de produção guardasse certos traços que ainda não o descaracterizam completamente e, ao mesmo tempo, adquirisse outros que significariam, talvez, uma mudança qualitativa" (23).

O leitor que me acompanhou até aqui talvez tenha concluído que a análise de Cardoso sobre a globalização pode ser mais ou menos plausível, mais ou menos convincente, mas tem a virtude indiscutível da simplicidade. Tal avaliação, contudo, é inteiramente falsa. Na verdade, quando o examinamos de perto, notamos facilmente que o discurso de Cardoso é repleto de ambigüidades.

Para começar, logo constatamos que o termo globalização aparece em variados contextos significando coisas muito diversas.

Em algumas sentenças ele denota um processo histórico - a totalidade das mudanças que estão transformando o capitalismo em algo ainda parcialmente indistinto, mas que, talvez, venha a constituir uma outra 
qualidade. Este é o sentido que o conceito adquire, por exemplo, nesta passagem: "A globlalização está longe de ser um fenômeno que avança de modo uniforme no plano internacional. Seu ritmo obedece a movimentos variados. O paradigma financeiro, por exemplo, é diferente do comercial. Neste último as resistências são muito maiores..." (24).

Já em outras, o termo globalização é usado para indicar uma configuração, um estado - o conjunto de condições que conferem à economia capitalista contemporânea um ordenamento inédito, como na afirmativa que se segue: "Durante décadas, os paises em desenvolvimento tentaram influenciar ... a construção de uma nova ordem internacional. A verdade é que ... essa nova ordem já estava sendo forjada e hoje atende pelo nome de globalização" (25).

Em alguns lugares, a globalização é um estado de coisas estabelecido, uma realidade pronta e acabada: "Queiramos ou não a globalização econômica é uma nova ordem internacional" (26). Em outros, ela surge como um cenário - o desenho que se insinua no horizonte, o qual, em alguma medida, está ao nosso alcance alterar: “[os governantes] não podem simplesmente ignorar esses condicionantes da realidade contemporânea, [mas] têm o dever de buscar nas contradições e nas inconsistências ... do sistema em gestação estratégias capazes de reafirmar a prioridade do interesse nacional" (27).

Seria possível explorar as curiosidades que resultam dessas e outras oscilações - por exemplo, a estranha noção de países excluídos de uma economia global, que - pelo fato mesmo de ser global-, de uma forma ou outra, os inclui, por definição. Mas não teríamos muito a ganhar seguindo esta trilha. A polissemia é um atributo geral da linguagem ordinária. Além de atestar o seu reduzido rigor, ela pouco nos informa sobre o discurso em causa.

Se queremos entender a maneira especificamente cardosiana de falar sobre a globalização, o ponto em que devemos fixar nossa atenção reside na ambivalência que se manifesta quando cotejamos dois tipos de argumentos. Considerem-se, por exemplo, as proposições a seguir.

"Também intimamente ligada à questão da globalização é a limitação que se impõe à capacidade dos Estados de escolher estratégias diferenciadas de desenvolvimento, de adotar politicas..." (28).

"A globalização modificou o papel do Estado num outro aspecto. Alterou radicalmente a ênfase da ação governamental, agora dirigida quase exclusivamente para..." (29). 
"A globalização também conduz a uma crescente uniformidade do arcabouço institucional e do quadro regulatório em todos os paises" (30).

Nestes - e em muitos outros - enunciados, a globalização surge reificada, como uma força impessoal, que se exerce coercitivamente, e de fora, sobre o fazer dos sujeitos. Os quais serão mais ou menos exitosos em seus planos de ação na medida mesma em que dela forem conscientes. A globalização "conduz”, "modifica”, “impõe”. O caráter imperativo da globalização fica ainda mais explícito no trecho seguinte, que elabora a última daquelas afirmações:

"Pois, para que possa desenvolver-se a globalização da produção, é preciso que as regras nos diferentes paises sejam similares, de modo que não venham a prevalecer, em qualquer pais, vantagens artificiais. Exemplo desta tendência é a introdução na Organização Mundial de Comércio, de padrões internacionais para os direitos de propriedade intelectual e para as regras de investimento" (31).

Não caberia examinar mais detidamente este argumento tão manejado que foi pelos defensores do projeto de lei sobre propriedade industrial, finalmente aprovado pelo Congresso brasileiro em maio de 1996, como desejava o governo, em versão que atendia plenamente os "requisitos da economia globalizada" (32).

Para efeitos da interpretação que venho construindo neste artigo, basta observar o contraste que se produz quando confrontamos o argumento de Cardoso com a palavra franca de Jagdish Bhagwati. Pouco conhecido no Brasil entre os não-especialistas, Bhagwati é professor da Universidade de Columbia, autoridade indiscutida em matéria de comércio exterior, ex-conselheiro do diretor-geral do GATT e, reconhecidamente, uma das expressões mundiais mais destacadas do liberalismo econômico na atualidade. É bom ouvi-lo, porque ele nos traz de volta à terra.

"A Lei Omnibus de Comércio e Competitividade, de 1978, reforçou a seção 301 da Lei de 1974 a fim de que os Estados Unidos pudessem fazer uso de retaliações comerciais contra paises estrangeiros que adotavam politicas unilateralmente chamadas por nós de desleais. Entre estas práticas, naturalmente, estava a negativa de proteger a propriedade intelectual, no nivel em que nós (nossos lobbies industriais) julgavam adequados... Observe que o nosso poder não é usado aqui para sancionar direitos de comércio vigentes. ... Trata-se, simplesmente, de demandas para mudar o mundo segundo a imagem reclamada pelos nossos lobbies." 
"Obviamente, quanto mais dura a proteção, maior tendem a ser os royalties que o nosso pessoal consegue. Mas as regras que maximizam essa proteção não são necessariamente ótimas, socialmente falando ... porque os beneficios da difusão de tecnologia são reduzidos pela proteção maior ... Interessantemente, como a defesa de nossa posição maxi-malista e terrivelmente fraca, em bases utilitárias, os porta-vozes do governo ... deslocaram a questão para uma abordagem em termos de 'direitos'. Assim, os embaixadores Yeuter, Hills e Kantor têm falado de 'pirataria' e 'roubo' ao reclamar proteção à propriedade intelectual. ... Os lobbies também vêem isto como um grande expediente para ganhar terreno. Afinal de contas, como você pode defender o roubo! Assim, nós obscurecemos o fato de que, na realidade, a questão-chave não é a de proteger, ou não proteger, mas de quanta proteção dar" (33).

Em sua dupla condição de estudioso e homem público, é improvável que Cardoso tenha muito a aprender com a lição do professor Bhagwati - até mesmo porque esteve à frente do Ministério das Relações Exteriores no momento em que o tema da propriedade intelectual era negociado na Rodada Uruguai, do Gatt, e como presidente empenhou-se pessoalmente na aprovação do referido projeto (34). Apenas, ao falar da matéria, terá julgado de seu dever, como político, omitir certas verdades que em outros contextos enuncia com toda naturalidade. Como o faz:

"Seria um erro grosseiro enxergar a globalização como resultante exclusiva das forças de mercado. Os contornos dentro dos quais o mercado atua são delineados politicamente, num contexto em que o fogo de poder entre as nações está sempre presente de forma inequívoca" (35).

"É do embate direto entre posições negociadoras distintas que nasce o arcabouço de regras e parâmetros que fixará os limites dentro dos quais os processos de globalização terão de operar" (36).

"Diria mesmo que o avanço do capitalismo terá mostrado que as expectativas deterministas arrefeceram diante de um mundo em que as escolhas sociais e, portanto, a politica, reinam soberanas" (37).

Esses trechos foram extraídos de uma conferência sobre globalização e politica exterior, feita na África do Sul. Nela, Cardoso denuncia a prática, que se tornou corriqueira, de atribuir notas aos países, segundo a sua maior ou menor capacidade de integrar-se nos fluxos internacionais de comércio, tecnologia e capital. Nesse procedimento, a globalização deixa a sua "condição de um dado da realidade" para converter-se em "um padrão que serve de base para juizos de valor". 
O problema de fundo levantado na conferência referida era: como entender as diferenças entre os Estados? Mais especificamente, como explicar os desvios - positivos ou negativos - em relação ao que é tido, genericamente, como a boa norma? Trata-se, como se vê, de um tema caro a Cardoso, e não surpreende constatar que ele recupera elementos de seu antigo repertório para se explicar. Vale a pena acompanhá-lo:

“Não será assim, por simples referência ao 'global' que poderemos entender o complexo jogo das forças em atuação no cenário internacional, nem as linhas de evolução politica e econômica que têm origem em modos diferenciados de desenvolvimento..."

"Na realidade, volto ao mesmo recurso metodológico que inspirou a 'teoria da dependência'. O capitalismo se expande de forma diferenciada e o elemento central para compreender a lógica de seu movimento está na ligação entre a dinâmica da expansão e as 'situações concretas' que encontra, que dizem respeito ao modo de articulação das leis de expansão com as estruturas sociais e politicas nacionais" (38).

E assim as extremidades se tocam: a globalização é um fenômeno novo, mas para dominá-lo intelectualmente não podemos dispensar os instrumentos da velha e boa teoria da dependência. Com sua ênfase na natureza política da economia internacional, a importância conferida à hierarquia entre os Estados, o cuidado dedicado à análise de situações concretas que resultam da interpenetração de processos externos e internos.

Dois argumentos claramente distintos. No primeiro, a globalização se apresenta como uma força irresistível - um processo ou uma ordem que permite, ou impede, que dita padrões de conduta aos quais os governantes devem aquiescer, sob pena de se condenarem ao fracasso - e a seus concidadãos às piores desgraças. Nessa linha de raciocínio, Cardoso bordeja com muita freqüência o discurso dos apologetas da economia global, parecendo mover-se, em companhia destes, num mundo determinista, onde o espaço para o exercício da escolha política inexiste, ou se encontra a tal ponto reduzido que as diferenças entre as alternativas subsistentes se tornam quase ilusórias.

No segundo, a globalização se mostra como um processo de transformação histórica, marcado por contradições e assincronias, em grande medida afetado por decisões políticas, que se desenvolve num movimento complexo - dialético - no contexto do qual as particularidades nacionais seguem desempenhando importante papel. 
Como entender o descompasso entre esses dois pontos de vista? Como reconciliá-los?

"Os homens fazem sua própria história, mas não a fazem como querem..." Em sua obra, como se sabe, Marx desenvolveu principalmente a segunda dessas duas orações; mas a conjunção adversativa não anula o que há de positivo na primeira delas. Condições objetivas, e subjetivas; determinação material, e vontade. Na tradição marxista, a tensão entre esses dois vetores traduziu-se no embate permanente entre tendências economicistas e voluntaristas que marca toda sua história. No próprio Marx, os dois elementos coexistem em equilíbrio instável. O aforismo famoso não resolve a questão; antes indica o quanto ela é problemática (39).

Face a problemas desse tipo - identificação de uma inconsistência importante em certo autor -, o comportamento usual é seguir o fio de sua obra, com o fim de verificar se, em algum nível, a dificuldade se resolve ou não se resolve. Em nosso caso, porém, adotar tal procedimento seria errar lamentavelmente o alvo. Em primeiro lugar, porque Cardoso nunca foi um pensador sistemático. Em segundo - de longe, mais importante - porque ele é, antes de tudo, um político prático. Se outros motivos não houvesse, bastariam esses dois para sugerir que na análise de seu discurso a atenção se concentrasse na dimensão pragmática.

Apesar de suas contradições - ou em razão delas -, quando o contemplamos nessa perspectiva, o discurso de Cardoso sobre a globalização se revela como um poderoso dispositivo retórico, o qual é sistematicamente usado na produção de razões que justificam aspectos diferentes de uma política - como toda política - contaditória. Esse dispositivo tem duas faces: uma delas desdobra-se em argumentos deterministas; a outra, em argumentos que ressaltam o papel da vontade. A relação entre elas, porém, não é definida: a passagem de um lado ao outro não é regida por nenhuma regra. E é importante que continue assim: na ausência de normas precisas, ou princípios claramente enunciados, fica a critério de quem está no comando acionar essa ou aquela bateria de acordo com as necessidades. Dotado de tal flexibilidade, esse dispositivo tem duplo emprego: na defensiva, permite desqualificar sistematicamente as críticas, apontadas como ineptas que são, ora por não enxergarem a "dura realidade dos fatos", ora por não reconhecerem os esforços que estão sendo feitos para transformá-la; na ofensiva, ele sustenta com argumentos a idéia, mil ve- 
zes repetida, de que "essa política é a única política possível”, e que fora dela há apenas o caos.

O exame mais cuidadoso desse dispositivo em funcionamento permite, ainda, avançar a hipótese que se segue. As duas modalidades de argumentos que ele produz vinculam-se a componentes distintos da política governamental. Os argumentos deterministas dão cobertura, basicamente, à política de estabilização ancorada no câmbio - "cidadela, protegida de qualquer ataque", na caracterização feliz de um observador avisado (40) -, cujos efeitos, traduzidos em desemprego crescente e taxas de crescimento renitentemente baixas, são naturalizados como conseqüências inevitáveis da globalização. Os argumentos de teor voluntarista, por sua vez, dão suporte às políticas setoriais - inclusive àquelas desenvolvidas pelo BNDES, em parte com o fim de atenuar o impacto negativo das medidas adotadas para preservar a política câmbial -, e à política exterior, domínio no qual, ao contrário do seu vizinho argentino, o governo brasileiro continua buscando atuar com relativa autonomia.

Seria possível, ademais, dar um passo além, e vincular as distintas facetas da política do governo Cardoso a subgrupos diferentes da equipe governamental, tentando estabelecer conexões significativas entre estes e os blocos que se defrontam no agitado mundo dos interesses privados. Ao fazer isso, poderíamos buscar um roteiro no próprio Cardoso, que no passado praticou esse tipo de exercício em alguma de suas melhores páginas. Mas devo abster-me. Este seria tema mais que suficiente para outro trabalho.

Acho mais próprio encerrar com uma palavra que me devolve ao problema levantado na abertura deste artigo. O quadro rapidamente sugerido aqui - de um governo que se ajusta mais ou menos passivamente às injunções internacionais; que se esforça para manter um certo grau de autonomia; que se apóia num bloco de interesses, no qual o interno e o externo se mesclam, e que incorpora, em sua própria composição, as clivagens existentes no interior deste compósito - um quadro como esse pode ser perfeitamente descrito na linguagem da teoria da dependência.

Esta constatação poderia nos incitar ao comentário de que Cardoso pratica hoje, como político, a dependência que ele teorizou, anos atrás, como sociólogo. Mas essa afirmativa não seria de todo justificada. A teoria da dependência surgiu num ponto determinado no tempo e no espaço. Pelas condições históricas que cercaram o seu aparecimento, ela veio associada a conteúdos político-ideológicos de caráter emancipatório, que se expressavam nas conseqüências práticas que dela se extraíam, bem as- 
sim como nos termos em que era vazada. Mas a dimensão programática não lhe era essencial. Como guia para a análise de situações concretas, ela deveria poder iluminar, tanto os desenvolvimentos históricos tendentes à superação da dependência, quanto aqueles que viessem reforçar esta última em suas formas mais perversas. Se é assim, mais próprio seria dizer que Cardoso se vale das antigas categorias para orientar-se no caminho que escolheu, como político, entre as várias alternativas que as mesmas permitiam divisar.

Mais do que responder a questões formuladas pelos debatedores ou por membros do público, vou aproveitar o tempo desta intervenção final para comentar certos aspectos do trabalho não-suficientemente esclarecidos em minha apresentação. Ao fazê-lo, vou me pronunciar a respeito de vários temas aflorados na discussão.

Inicialmente, para escrever esse artigo eu me impus uma autocontenção muito grande. Em primeiro lugar, abstive-me de discutir com o autor que estava analisando. A questão do valor de verdade de suas proposições, da validade de suas afirmativas, essa questão pouco me concernia. O que me interessava, fundamentalmente, era ver como se construíam os argumentos e qual o uso que deles fazia em sua prática discursiva o intelectual-político Fernando Henrique Cardoso.

Nesse sentido, silenciei o que penso a respeito das questões de conteúdo abordadas nos documentos que examinei - salvo em uma ou outra ocasião, e mesmo assim de forma muito oblíqua. Isto vale mesmo para a categoria de globalização e para a teoria (ou análise) da dependência em quaisquer das versões propostas, desde que se desatou, na América Latina, o debate sobre o tema.

Em relação à primeira, vou resumir o meu ponto de vista num comentário breve. Concordo com o Paulo Nogueira. O termo globalização não acrescenta grande coisa à inteligência da economia capitalista mundial.

Vejam, acabamos de ouvir aqui uma exposição brilhante sobre o que há de novo na economia mundial nos dias que correm. Mas, sempre que, no debate sobre o tema da globalização, ouço alguém ou leio textos que seguem nessa direção, o comentário que me ocorre é o seguinte: o próprio do capitalismo é a renovação, a revolução permanente das técnicas, das maneiras de produzir e das instituições no contexto das quais tal atividade inovadora se efetua. Apontar a presença de elementos novos na economia mundial não é dizer que ela está diante de alguma coisa nova. 
O que temos de nos perguntar é se ganhamos algo, cognitivamente, ao sintetizar o que há de novo no presente da economia mundial com essa categoria. E aí eu tenho minhas dúvidas. Pois quando examino o discurso da globalização, mesmo no caso de um autor específico, como Fernando Henrique Cardoso, vejo que esta é uma noção velha, autocontaditória, uma noção que se desfaz em pedaços quando cobrada mais rigorosamente. Devemos manter muito clara a distinção entre conceitos, ou noções, e as realidades que procuramos denotar com esses meios. O próprio do mito é desconhecer essa diferença. E isto acontece muito freqüentemente no discurso da globalização. Por exemplo, em frases como esta, que todos nós já nos cansamos de ouvir: "podemos gostar disso, ou não, mas a globalização é um fato: não podemos desconbecê-la, muito menos aboli-la". Como se rejeitar o conceito fosse o mesmo que ignorar os fatos que, mais ou menos confusamente, ele refere.

Outro aspecto a destacar é que o discurso da globalização perde muitas vezes de vista o fato que o capitalismo não é uma economia: é uma economia politica. Essa é a grande lição de Wallerstein. Trata-se de uma economia que nasce e se reproduz nos quadros de uma estrutura política fragmentada, composta de um número variável de unidades políticas que se reconhecem mutuamente como distintas e independentes. O capitalismo tem uma forma política própria. Em termos globais, o sistema interestatal é a configuração política que lhe corresponde.

Quando nos colocamos nessa perspectiva, vemos que jogar com pares conceituais, como ecomonia global e Estado, e falar da crise do Estado sob o impacto da globalização, é tomar um falso caminho. Porque $o$ Estado, como ente singular, não existe. O capitalismo nos confronta sempre com uma pluralidade de Estados. E estes são desiguais, hierarquizados e desempenham papéis distintos.

A globalização, a liberalização de bens e serviços, as cadeias produtivas globais e os fluxos financeiros instantâneos - esses fenômenos não surgem espontaneamente, como propriedades emergentes da economia capitalista. Em grande medida, eles são resultados de decisões e de políticas estatais. E não de quaisquer Estados: de um pequeno número deles, dentre os quais sobressai o Estado norte-americano.

Desde meados da década passada estamos assistindo a um processo de renegociação global das regras que regulam o comércio de bens e serviços, os direitos de propriedade e os investimentos. Esse processo de reorganização institucional foi lançado com a abertura da Rodada Uruguai do Gatt, e ele ainda não está concluído. Hoje, a OCDE está discutindo um 
Acordo Multilateral de Investimentos que, se passar como foi proposto, vai eliminar nossa possibilidade de formular e implementar políticas industriais, vai tornar utópica, fantasiosa, ilusória qualquer idéia de um projeto nacional de desenvolvimento. Outro tanto poderia ser dito a respeito das negociações visando a integração regional em escala hemisférica ora em andamento. E estão avançados os preparativos para outra rodada de negociações globais no âmbito da Organização Mundial do Comércio (a assim chamada Rodada do Milênio). Se queremos falar de economia política internacional para valer, temos de lidar com o que está acontecendo nesse plano. Temos de identificar as questões que estão postas na mesa, temos de indagar quais os interesses envolvidos em cada uma delas, qual o seu peso respectivo, como se alinham, como se configura o conflito, e para que cenários ele aponta. Quando tentamos fazer isso, pouca ajuda encontramos no discurso da globalização.

Agora, a dependência. Até que ponto o político Fernando Henrique Cardoso pratica hoje a dependência que ele teorizou no passado como sociólogo? Para começar, gostaria de dizer: eu não sou um especialista em teoria da dependência. Não sou! Por circunstâncias pessoais - eu me formei no Rio de Janeiro, em uma instituição onde o debate sobre o tema não foi tão forte quanto em outros lugares -, por esse ou aquele motivo, o meu envolvimento com o debate sobre a dependência foi muito superficial. Obviamente, eu lia o que me chegava às mãos. Mas estudar, estudar de verdade, isto é algo mais recente.

Pois bem, a conclusão a que cheguei é que a teoria da dependência - penso especificamente no livro de Cardoso \& Faletto - surgiu como tentativa de dar resposta a um problema histórico-político bem claro: o golpe de 64, a adesão praticamente unânime que recebeu do empresariado brasileiro, e o surto de crescimento que, contrariando as expectativas gerais da inteligência econômica de oposição, começava a despontar já naquele momento. Era uma questão palpitante, de implicações políticas evidentes, e isto explica em boa medida o enorme sucesso do livro.

Mas o que o texto de Cardoso \& Faletto oferecia ao leitor não era uma análise de conjuntura. Grande parte da força persuasiva do argumento sobre o presente advinha do modelo interpretativo mais amplo, que se expressava sob a forma de uma reconstrução original, rica e parcimoniosa de todo o processo histórico latino-americano, de independência em diante. Nessa interpretação, o determinismo das estruturas é apenas parcial. No grande painel que desenha, as situações mais perversas de dependência - com as forças sociais em que se sustentam comportam igualmente elementos de resistência e de transformação, a 
qual, em princípio, pode apontar para uma nova modalidade de dependência, ou para uma ordem capaz de alimentar a promessa de libertação. É por isso que no final do artigo digo que na teoria da dependência, tal como apresentada por Enzo Faletto e Fernando Henrique Cardoso, a dimensão explanatória é muito mais importante que a dimensão prescritiva.

E assim, sustento também ser possível afirmar que Fernando Henrique Cardoso pratica a dependência que teorizou no passado. Mas apenas no sentido preciso de que a sua ação como político - suas escolhas, suas alianças, suas abstenções - pode ser descrita e interpretada à luz daquele esquema analítico. O que não me convence, não me parece plausível, é a idéia de que nos primeiros escritos sobre a dependência já estivesse contida, como que em germe, a política que Fernando Henrique Cardoso realiza agora, 30 anos depois, como presidente. Esta política não é a materialização de idéias previamente concebidas: é o resultado de uma história longa, que se bifurcou em vários pontos, e as escolhas que o seu protagonista fez em cada um deles foram ditadas por circunstâncias e motivações que muito pouco tinham a ver com a teoria da dependência, ou outra teoria qualquer.

E, para concluir, Marx e Weber produziram obras de extensão e de complexidade enormes. Daí a dificuldade que tenho em pensar o marxismo, o weberianismo, ou qualquer outro desses ismos como algo a que eu possa me referir assertivamente, de forma simples. Por esse motivo, a pergunta sobre se tal ou qual teoria é marxista ou weberiana não tem para mim a menor relevância. O que interessa não é a filiação da teoria da dependência, mas os seus efeitos. Efeitos políticos e efeitos de conhecimento. Isto eu discuto. O resto ..., é o resto. Não tem importância alguma.

Notas

1 Fernando Henrique Cardoso, A dependência revisitada. In: As idéias e seu lugar. Ensaios sobve as teorias do desenvolvimento. Petrópolis, Vozes, 1993, p. 84 e 89.

2 Peter A. Hall (ed.), The political power of economic ideas. Keynesianism across nations. Princeton, Princeton University Press, 1989.

3 Cf., entre outros, Goldstein, Judith \& Robert Keohane, Ideas and foreign policy: beliefs, institutions, and political change. Ithaca, Cornell Unversity Press, 1993; Alexander Wendt, Anarchy is what State makes of it: the social 
construction of power politics, in: International Organization, v. 46, n. 2, p. 391-425, 1992; $i d$, Collective identity formation and the international State, in: American Political Science Review, v. 88, n. 2, p. 384-396, 1994; Chris Brown, International relations theory. New normative approaches, Londres, Harvester Wheatsheaf, 1992; Steve Smith, Ken Booth \& Marysia Zalewski (eds.). International theory: positivism and beyond, Cambridge, Cambridge University Press, 1996.

4 Cf. José Luis Fiori, Folha de S. Paulo, 3 jul. 1994, p. 6-6; Fernando Henrique Cardoso, Reforma e imaginação, Folha de S. Paulo, 10 jul. 1994. Este último foi republicado em Paulo Nogueira Batista (ed.), Em defesa do interesse nacional. Desinformação e alienação do patrimônio público, Rio de Janeiro, Paz e Terra, 1995, p. 173-180.

5 Esse é o roteiro seguido por Peter Gourevitch em seu conhecido livro Politics in hard times. Comparative responses to international economic crisis, Ithaca, Cornell University Press, 1987.

6 Ambas publicadas no número 10 da série Idéias \& Debates, do Instituto Teotônio Vilela. Brasília, 1997.

7 Brasílio Sallum Jr., Entrevista com Fernando Henrique Cardoso, Lua Nova, n. 39, p. 11-32, 1997.

8 Este trabalho estava praticamente terminado quando tomei conhecimento do livro contendo a série de nove longas entrevistas concedidas por Fernando Henrique Cardoso ao jornalista Roberto Pompeu de Toledo, uma delas sobre o tema tratado nestas páginas. Por absoluta carência de tempo, não pude levá-la em conta na redação do artigo. Mas tal fato não o prejudica. Pelo contrário. Concluída a leitura do sexto capítulo - Globalização - as observações críticas que pontuam o meu texto se mantêm, enquanto a interpretação geral nele desenvolvida me parece ser amplamente corroborada. Cf. Roberto Pompeu de Toledo, O presidente segundo o sociólogo. Entrevista de Fernando Henrique Cardoso a Roberto Pompeu de Toledo, São Paulo, Companhia das Letras, 1998, p. 81-102.

9 Cf. Michael Porter, Competition in global industries: a conceptual framework, in: M. Porter (ed.), Competition in global industries, Boston, Harvard Business School Press, 1986, p. 15-60.

10 Cf. Mapping the global condition, in Mike Featherstone (ed.), Global culture. Nationalism, globalization and modernity, Londres, Sage, 1990, p. 15-30.

11 Roland Robertson, Globalization. Social theory and global culture. Londres, Sage Publications, 1994, p. 6-7.

12 Basta mencionar, no Brasil, a linha de trabalho desenvolvida por Octávio Ianni e por Renato Ortiz, e a literatura internacional sobre esses temas. 
13 A esse respeito, cf., Daniele Archibugi \& David Held (eds.), Cosmopolitan democracy. An agenda for a new world order, Londres, Polity Press, 1995 e, principalmente, o importante livro de Held, Democracy and the global order. From the modern State cosmopolitan governance, Stanford, Stanford University Press, 1995.

14 Fernando Henrique Cardoso, Nunca fui um neoliberal. Esquerda 21, p. 36.

15 Id., Conseqüências sociais da globalização, op. cit., p. 11.

16 Id., O impacto da globalização nos países em desenvolvimento, op. cit., p. 19.

17 Id., Introdução, in As idéias e seu lugar. Ensaios sobre as teorias do desenvolvimento, $2^{\text {a }}$ ed., Rio de Janeiro, Vozes, 1993, p. 20. O texto foi originalmente publicado em 1980.

18 Id. Ibid., p. 23. A frase completa-se com a seguinte oração: “... a expansão do mercado interno passa a ser fundamental para permitir a circulação das mercadorias e a continuidade do processo produtivo do resto da economia." $\mathrm{O}$ que poderia ser interpretado como alusão a uma característica não mais vigente na economia globalizada dos nossos dias. Mas essa interpretação não encontraria apoio na realidade econômica, nem nas análises que dela oferece o próprio Cardoso.

19 Fernando Henrique Cardoso, Conseqüências Sociais da Globalização, op. cit., p. 17.

20 Cf. Cardoso, Empresário industrial e desenvolvimento econômico, São Paulo, Difusora Européia do Livro, 1964, versão publicada de sua tese de Livre Docência.

21 Id., ibid., p. 17.

22 Não é preciso recuar muito no tempo para encontrar Cardoso falando do assunto em outra linguagem. Leia-se por exemplo, esta passagem: "Estes fatos deram origem... à noção (ideológica) de que o mundo contemporâneo marcha para uma revalorização do mercado e do liberalismo, quando, na verdade, as negociações são conduzidas politicamente pelos governos, as alianças econômicas soldaram interesses entre grandes oligopólios de produção e distribuição, reunificados à escala mundial e criou-se um novo sistema de 'planejamento espontâneo e prospectivo' não-contraditórios com os já referidos valores de liberdade individual. ... Alternativas econômicas para a América Latina, palestra proferida em Salamanca, em 20/7/90, e publicada como adendo na segunda edição do livro As idéias e seu lugar, op. cit., p. 234.

23 Globalização e política internacional. Conferência pronunciada em Johannesburgo, 27-11-1996. 
24 O Impacto da globalização nos países em desenvolvimento: riscos e oportunidades, op. cit., p. 21-22.

25 Id., Ibid., p. 23.

26 Conseqüências sociais da globalização, op. cit., p. 21.

27 O impacto da globalização nos países em desenvolvimento, op.cit., p. 21.

28 Id., ibid.

29 Conseqüências sociais da globalização, op. cit., p. 8.

30 Id., Ibid., p. 7.

31 Id., ibid.

32 Cf. Diário Oficial, 15 maio 1996.

33 Jagdish Bhagwati, Which way? Free trade or protection? (entrevista). Challenge, p. 20. jan/fev. 1994. Ao denunciar os interesses muito localizados que movem a investida norte-americana em defesa de um novo regime de propriedade intelectual, Bhagwati reata com a mais pura tradição do liberalismo econômico, que se expressou vivamente na oposição de um órgão como a revista The Economist à adoção de padrões internacionais de proteção à propriedade intelectual no último quartel do século passado. Sobre o tema da propriedade intelectual, seu significado econômico e as injunções políticas que ele envolve, cf., entre outros, Edith T. Penrose, The economics of the international patent system, John Hopkins Press, 1951; David F. Noble, America by design. Science, technology, and the rise of corporate capitalism. Oxford, Oxford University Press, especialmente o capítulo 6, The corporation as inventor. Patent-law reform and patent monopoly, p. 84-109; Rennée Marlin-Bennett, International Intellectual Property Rights in a Web of Social Relations, Science Communication, v. 17, n. 2, 1995, p. 119-136; Paul N. Doremus, The externalization of domestic regulation: intellectual property rights reform in a global era, ibid., p. 137-162; Susan K. Sell, The origins of a trade-based approach to intellectual property protection: the role of industry associations, ibid., p. 163-185. Para uma discussão em profundidade do problema da uniformização institucional no âmbito da economia globalizada, Cf. J. Bhagwati \& R. E. Hudec (eds.), Fair trade and harmonization. Prerequisites for free trade?, v. I (Economic analysis) e v. II (Legal analysis), Cambridge, The MIT Press, 1996.

34 Sobre o tema da propriedade intelectual do ponto-de-vista das relações externas do Brasil, conforme Maria Helena Tachinardi, A guerra das patentesO conflito Brasil X EUA sobre propriedade intelectual. São Paulo, Paz e Terra, 1993 - livro cujo prefácio, aliás, é assinado por Cardoso. 
35 Globalização e política internacional, op. cit.

36 Ibid.

37 Ibid.

38 Ibid.

39 Cf. Alvin Gouldner, The two marxisms: contradictions and anomalies in the development of theory, New York, Seabury, 1980.

40 Cf. Edward J. Amadeo, Cidadela para o câmbio, O Estado de S. Paulo, 15 mar. 1997. Vale a pena ler a justificativa da metáfora: "Mas a política cambial não pode mudar. E não pode mudar por duas razões. Primeiro, porque a tentativa de desvalorizar o câmbio seria contrária à lógica do plano de estabilização. Segundo, e esta é a razão mais sutil, porque, uma vez escolhido o caminho da abertura e da liberalização das contas comercial e de capitais, o espaço de manobra para fazer alterações na política cambial se torna muito mais restrito."

RESUMO - O PROBLEMA da relação entre idéias e políticas tem suscitado vivo debate nas Ciências Sociais. Inscreve-se nesse quadro a discussão travada no Brasil a respeito da continuidade/descontinuidade entre a teoria da dependência e a ação de Fernando Henrique Cardoso, como presidente da República. Antes de se pronunciar sobre tais afinidades, o artigo examina detidamente o discurso de Cardoso sobre a globalização. Constatando, neste, a presença de dois argumentos contraditórios sobre o tema, propõe uma interpretação que responde à dupla pergunta: sobre o significado político desse discurso e sobre os seus vínculos com a teoria da dependência.

Sebastião C. Velasco e Cruz é professor do Departamento de Ciência Política do Instituto de Filosofia e Ciências Humanas da Unicamp. É autor, entre outros, dos livros Empresariado e Estado na transição brasileira (Editora da Unicamp) e Estado e economia em tempo de crise (Relume Dumará/Editora da Unicamp). 